\title{
Mental Distress and Associated Factors Among Hospitalized Medical-Surgical Adult Inpatients in Public Hospitals, Addis Ababa, Ethiopia, 2020: Cross-Sectional Study
}

\author{
Shegaw Tesfa iD \\ Berhanu Wordofa Giru (iD ${ }^{2}$ \\ Tadesse Bedada ${ }^{2}$ \\ Debela Gela (iD) ${ }^{2}$ \\ 'Department of Nursing, College of \\ Health Science, Wolkite University \\ (WKU), Wolkite, Ethiopia; ${ }^{2}$ School of \\ Nursing and Midwifery, College of Health \\ Science (CHS), Addis Ababa University \\ (AAU), Addis Ababa, Ethiopia
}

Background: Mental distress is a mental or psychological syndrome which influences the health status, treatment effectiveness, and quality of care of a hospitalized medical-surgical inpatient. It is more common in a hospital setting than in a community setting. Thus, the aim of this study was to assess the prevalence of mental distress and associated factors among hospitalized medical-surgical adult inpatients in public hospitals, Addis Ababa, Ethiopia, 2020. Methods: An institutional-based cross-sectional study was conducted among a total of 408 study subjects from March 1 to 30, 2020. The study participants were recruited by systematic random sampling technique and data were collected using an interviewer-administered questionnaire. The collected data were entered into EpiData 3.1 and exported to SPSS version 26 for analysis, and then binary and multiple logistic regressions were performed to check the association between dependent and independent variables.

Results: The prevalence of mental distress among hospitalized medical-surgical adult inpatients in public hospitals was $53.1 \%$. Variables of being married $[\mathrm{AOR}=2.67 ; 95 \%$ CI $(1.065,6.683)]$, private employee $[\mathrm{AOR}=2.21 ; 95 \% \mathrm{CI}(1.001,4.900)]$, daily laborer $[\mathrm{AOR}=4.70 ; 95 \% \mathrm{CI}(1.218,18.215)]$, rural residence $[\mathrm{AOR}=1.85 ; 95 \%$ CI $(1.047$, $3.264)]$, drinking alcohol $[\mathrm{AOR}=1.68 ; 95 \% \mathrm{CI}(1.025,2.740)]$, previous psychiatric illness $[\mathrm{AOR}=3.40 ; 95 \% \mathrm{CI}(1.078,10.737)]$ and comorbidity $[\mathrm{AOR}=1.93 ; 95 \%$ CI $(1.200$, 3.094)] were found to be significantly associated with mental distress.

Conclusion: The prevalence of mental distress was high and being married, a private employee, daily laborer, living in a rural area, previous history of psychiatric illness, alcohol use, and comorbidity were associated with mental distress among hospitalized adult inpatients. Therefore, healthcare providers should provide special consideration to those groups of patients admitted to the hospital.

Keywords: mental distress, hospitalized medical-surgical adult inpatients, public hospitals

\section{Introduction}

According to the world health organization (WHO), mental health is a state of well-being in which an individual can realize his or her abilities, interact positively with others, cope with stressors of life and work productively, fruitfully, and contribute to his or her family and community. WHO noted not exclusively the absence of mental illness, but also addresses the concept of mental wellness, no health without mental health. ${ }^{1}$

American Psychiatric Association's Diagnostic and Statistical Manual of mental disorders fourth edition (DSM-IV) defines mental disorder as a clinically important
Correspondence: Debela Gela

Email debegela@gmail.com 
behavioral or psychological syndrome in a person associated with present distress or disability with a significantly increased risk of suffering death, pain, disability. It is a specific diagnosis made by trained mental health professionals after formal psychiatric assessment. ${ }^{2}$

Although mental disorders have often been neglected because of non-specificity in diagnosis and clinical manifestation, long-term treatment is required and various sociocultural myths and belief systems are associated with it. ${ }^{3}$

Mental distress is a wider concept of mental health problems which comprises mental disorders that may not fall into specific standard diagnostic criteria. ${ }^{4}$ It is a public health issue conceptualized by stress, confusion, emotions, hallucination, depression, anxiety, panic or somatic and other psychiatric symptoms, and mostly symptoms are experienced by persons without actually being ill in a medical sense and interfere in their day to day activity. ${ }^{5}$

Mental distress is a collection of mental health abnormalities that may not be grouped into standard diagnostic criteria, which is characterized by symptoms of anxiety, depression, insomnia, fatigue, irritability, forgetfulness, difficulty in concentrating, and somatic symptoms such as sleep problems, headache, and backache. ${ }^{6}$ It is more common in a hospital setting than community setting; which influences the health status, treatment effectiveness, and quality of care in hospitalized patients. ${ }^{7}$ Surveys showed that 20 to $60 \%$ of patients admitted to a hospital suffer from the most common mental disorders like stress, depression, and anxiety. ${ }^{8}$ Therefore, the purpose of this study was to assess the prevalence of mental distress and its associated factors among hospitalized medical-surgical adult inpatients in public hospitals, Addis Ababa, Ethiopia, 2020.

\section{Methods and Materials}

\section{Study Area and Period}

Addis Ababa, the capital city of the Federal Democratic Republic of Ethiopia, located at the center of the country with 10 sub-cities and 116 Woredas has a total population of around 3.4 million according to Ethiopian population projection for all regions in Wereda level from 20142017. ${ }^{9}$ Its land area is estimated to be $530 \mathrm{Km}^{2}$ with altitude ranging from 2200 to 3000 meters above sea level, with average temperature of $22.8^{\circ} \mathrm{C}$ and an average rainfall of $1180.4 \mathrm{~mm}^{3}$. It has 53 hospitals of which 13 are public and 40 are private. The setting of the study was in four randomly selected Addis Ababa public hospitals of Ethiopia: Tikur Anbessa Specialized Hospital (Black Lion Specialized Hospital) had a total of 646 inpatients, from this 374 were adult inpatients; St. Paulos hospital had a total of 502 inpatients, from this 237 were adult inpatients; Yekatit 12 hospital had a total of 359 inpatients, from this 139 were adult inpatients and Zewditu hospital had a total of 208 inpatients, from this 72 were adult inpatients at the time. The study was conducted from March 1 to 30, 2020.

\section{Study Design and Population}

An institution-based cross-sectional study was conducted. All randomly selected hospitalized medical-surgical adult (18 years and above) inpatients available at selected public hospitals during the study period were included, except patients who were unable to communicate, with critical illnesses, physical speech impairment, mental disability, and post-anesthesia during the data collection period.

\section{Sample Size Determination and Sampling Procedure}

The sample size was calculated by using the single population proportion formula, considering the following assumptions; the prevalence of mental distress was $58.6 \%$ in Gondar University hospital among medical-surgical adult inpatients, ${ }^{10} 95 \%$ confidence interval, and 5\% margin of error. The final sample size including the non-response rate yielded 408 patients. Four hospitals were selected using the simple random sampling lottery method, which was TASH (Tikur Anbessa Specialized Hospital), St. Paulos hospital, Yekatit 12 hospital, and Zewditu hospital. A total of 408 study subjects were selected from 822 reference populations using systematic random sampling every $\mathrm{k}=2$ interval.

\section{Study Variables}

The dependent variable was mental distress and the independent variables included sociodemographic factors (age, sex, religion, ethnicity, residence, occupation, monthly income, marital status, education status), substance userelated variables (tobacco use, alcohol use, chat use, illegal drug use), psychosocial variables (social support, living condition), clinical related variables (previous psychiatric history, psychiatric illness after admission, psychiatric consultation, family history of psychiatric illness, previous hospital admission, ward admitted, comorbidity, hospital stay). 


\section{Data Collection Tool and Procedure}

The Amharic version of the questionnaire was used for data collection. First, the questionnaire was prepared in the English language then translated to Amharic and back to English. Two clinical staff members were used as supervisors and four nursing students were used as data collectors with half-day training. Self-Reporting Questionnaire was a dichotomous type scale to determine the prevalence of mental distress in adult inpatients. The SRQ-25 was a standardized questionnaire with 25 item questions adapting the SRQ for Ethiopian Populations for culturally sensitive psychiatric screening instruments. This tool was validated in Ethiopia and other low socioeconomic countries. In Ethiopia, there was a sensitivity of $86 \%$ and specificity of $84 \%$ with a cut-off point of $8 .^{11}$

\section{Data Processing and Analysis}

First, the data were checked for its completeness and consistency, and then coded and entered in EpiData version 3.02 software. After entry, data were exported to statistical package for social science (SPSS) version 26 for analysis. Descriptive analysis using frequencies, proportions, graphs were performed to describe the number and percentage of sociodemographic characteristics of the sample and other variables. A binary logistic regression analysis model was used to identify associated factors of mental distress. This was done by odds ratio and p-value with $95 \%$ confidence interval (CI). Explanatory variables with a $p$-value of $\leq 0.25$ in the bivariate logistic regression were entered into a multivariate logistic regression analysis to control possible confounding. HosmerLemeshow's test was found to be insignificant ( $\mathrm{p}$-value $=$ 0.999) and Omnibus tests were significant $(\mathrm{P}$-value $=0.001)$ which indicates the model was fitted. A p-value of less than 0.05 was used to declare a level of statistical significance and an adjusted odds ratio (AOR) with 95\% CI was estimated to identify significantly associated variables with the dependent variable, mental distress. Finally, the results were presented in text, tables, and graphs based on the types of data.

\section{Results}

\section{Socio-Demographic Characteristics of the Study Participants}

In this study, the data were collected from 401 respondents through face-to-face interviews with a response rate of $98.3 \%$. Among those, 214 (53.4\%) were men, 89 (22.2\%) were in the age group of 25-34 and the mean age of the study participants was 40.8 years with a standard deviation of \pm 15.72 . From the study participants, 157 (39.2\%) were of Amhara ethnicity and
$260(64.8 \%)$ lived in urban areas, 239 (59.6\%) were orthodox religion, 237 (59.1\%) were married, 104 (25.2\%) had primary education, and 98 (24.4\%) were farmers. The majority of the respondents had low income: 213 (53.1\%) (Table 1).

Table I Sociodemographic Characteristics of Study Participants in Public Hospitals, Addis Ababa, Ethiopia, 2020 ( $n=408)$

\begin{tabular}{|c|c|c|c|}
\hline Variables & Category & Frequency & Percent (\%) \\
\hline \multirow[t]{6}{*}{ Age } & 18 to 24 & 69 & 17.2 \\
\hline & 25 to 34 & 89 & 22.2 \\
\hline & 35 to 44 & 79 & 19.7 \\
\hline & 45 to 54 & 72 & 18.0 \\
\hline & 55 to 64 & 58 & 14.5 \\
\hline & 65 and more & 34 & 8.5 \\
\hline \multirow[t]{2}{*}{ Sex } & Female & 187 & 46.6 \\
\hline & Male & 214 & 53.4 \\
\hline \multirow[t]{5}{*}{ Religion } & Orthodox & 239 & 59.6 \\
\hline & Muslim & 90 & 22.4 \\
\hline & Protestant & 60 & 15.0 \\
\hline & Catholic & 8 & 2.0 \\
\hline & Others & 4 & 1.0 \\
\hline \multirow[t]{4}{*}{ Marital status } & Single & 116 & 28.9 \\
\hline & Married & 237 & 59.1 \\
\hline & Divorced & 22 & 5.5 \\
\hline & Windowed & 26 & 6.5 \\
\hline \multirow[t]{6}{*}{ Ethnicity } & Amhara & 157 & 39.2 \\
\hline & Oromo & 114 & 28.4 \\
\hline & Tigray & 33 & 8.2 \\
\hline & Gurage & 45 & 11.2 \\
\hline & Silte & 25 & 6.2 \\
\hline & Others & 27 & 6.7 \\
\hline \multirow[t]{2}{*}{ Residence } & Rural & 141 & 35.2 \\
\hline & Urban & 260 & 64.8 \\
\hline \multirow[t]{5}{*}{ Education } & $\begin{array}{l}\text { Cannot read and } \\
\text { write }\end{array}$ & 84 & 20.9 \\
\hline & Can read and write & 61 & 15.2 \\
\hline & Primary & 101 & 25.2 \\
\hline & Secondary & 87 & 21.7 \\
\hline & Higher education & 68 & 17.0 \\
\hline \multirow[t]{7}{*}{ Occupation } & Government worker & 68 & 17.0 \\
\hline & Private employee & 84 & 20.9 \\
\hline & Merchant & 61 & 15.2 \\
\hline & Farmer & 98 & 24.4 \\
\hline & Housewive & 49 & 12.2 \\
\hline & Daily laborer & 16 & 4.0 \\
\hline & Others & 25 & 6.2 \\
\hline \multirow[t]{2}{*}{ Income } & Low income & 213 & 53.1 \\
\hline & High income & 188 & 46.9 \\
\hline
\end{tabular}




\section{Substance Use-Related Factors of Mental Distress}

From the study participants, 49 (12.2\%) used chat, 132 (32.9\%) used alcohol, 18 (4.5\%) smoked, and 3 (0.7\%) used other illegal substances like hashish (Table 2).

\section{Psychosocial Factors of Mental Distress}

Among the study participants, 332 (82.8\%) were living with their family, $59(14.7 \%)$ were living alone, and $10(2.5 \%)$ were living with others. In this study, 277 (69.1\%) had low social support and 124 (30.9\%) had high social support (Table 3).

\section{Clinical-Related Factors of Mental}

\section{Distress}

Among the study participants, 213 (53.1\%) were admitted to the medical ward, $199(49.6 \%)$ had a previous history of hospitalization, 157 (39.2\%) had comorbidity, 144 (35.9\%) were staying at the hospital for $<1$ week, 119 (29.7\%) stayed for 1 to 2 weeks, and 138 (34.4\%) stayed for more than 2 weeks, $61(15.2 \%)$ had a family history of psychiatric illness, 17 (4.2\%) had received psychiatric counseling, $18(4.5 \%)$ had previous history of psychiatric condition, and $6(1.5 \%)$ had a current psychiatric condition (Table 4$)$.

Table 2 Substance Use Related Factors of Study Participants in Public Hospitals, Addis Ababa, Ethiopia, $2020(n=408)$

\begin{tabular}{|l|l|l|l|}
\hline Variables & Category & Frequency & Percent (\%) \\
\hline Chat used & Yes & 49 & 12.2 \\
& No & 352 & 87.8 \\
\hline Alcohol used & Yes & 132 & 32.9 \\
& No & 269 & 67.1 \\
\hline Tobacco used & Yes & 18 & 4.5 \\
& No & 383 & 95.5 \\
\hline Other drugs used & Yes & 3 & 0.7 \\
& No & 398 & 99.3 \\
\hline
\end{tabular}

Table 3 Psychosocial Factors of Study Participants in Public Hospitals, Addis Ababa, Ethiopia, $2020(n=408)$

\begin{tabular}{|l|l|l|l|}
\hline Variables & Category & Frequency & $\begin{array}{l}\text { Percent } \\
\text { (\%) }\end{array}$ \\
\hline Living condition & Alone & 59 & 14.7 \\
& Family & 332 & 82.8 \\
& Others & 10 & 2.5 \\
\hline Social support & Low social support & 277 & 69.1 \\
& High social support & 124 & 30.9 \\
\hline
\end{tabular}

Table 4 Clinical-Related Factors of Study Participants in Public Hospitals, Addis Ababa, Ethiopia, $2020(n=408)$

\begin{tabular}{|c|c|c|c|}
\hline Variables & Category & Frequency & $\begin{array}{l}\text { Percent } \\
\text { (\%) }\end{array}$ \\
\hline $\begin{array}{l}\text { Previous history of } \\
\text { a psychiatric condition }\end{array}$ & $\begin{array}{l}\text { Yes } \\
\text { No }\end{array}$ & $\begin{array}{l}18 \\
383\end{array}$ & $\begin{array}{l}4.5 \\
95.5\end{array}$ \\
\hline $\begin{array}{l}\text { Current psychiatric } \\
\text { condition }\end{array}$ & $\begin{array}{l}\text { Yes } \\
\text { No }\end{array}$ & $\begin{array}{l}6 \\
395\end{array}$ & $\begin{array}{l}1.5 \\
98.5\end{array}$ \\
\hline $\begin{array}{l}\text { Contact with psychiatric } \\
\text { counseling }\end{array}$ & $\begin{array}{l}\text { Yes } \\
\text { No }\end{array}$ & $\begin{array}{l}17 \\
384\end{array}$ & $\begin{array}{l}4.2 \\
95.8\end{array}$ \\
\hline $\begin{array}{l}\text { Family history of } \\
\text { psychiatric illness }\end{array}$ & $\begin{array}{l}\text { Yes } \\
\text { No }\end{array}$ & $\begin{array}{l}61 \\
340\end{array}$ & $\begin{array}{l}15.2 \\
84.8\end{array}$ \\
\hline Ward admitted & $\begin{array}{l}\text { Medical } \\
\text { Surgical }\end{array}$ & $\begin{array}{l}213 \\
188\end{array}$ & $\begin{array}{l}53.1 \\
46.9\end{array}$ \\
\hline $\begin{array}{l}\text { Previous history of } \\
\text { hospitalization }\end{array}$ & $\begin{array}{l}\text { Yes } \\
\text { No }\end{array}$ & $\begin{array}{l}199 \\
202\end{array}$ & $\begin{array}{l}49.6 \\
50.4\end{array}$ \\
\hline Comorbidity & $\begin{array}{l}\text { Yes } \\
\text { No }\end{array}$ & $\begin{array}{l}157 \\
244\end{array}$ & $\begin{array}{l}39.2 \\
60.8\end{array}$ \\
\hline Time stayed in hospital & $\begin{array}{l}<\text { I week } \\
\text { I-2 week } \\
>2 \text { weeks }\end{array}$ & $\begin{array}{l}144 \\
119 \\
138\end{array}$ & $\begin{array}{l}35.9 \\
29.7 \\
34.4\end{array}$ \\
\hline
\end{tabular}

\section{The Prevalence of Mental Distress}

The prevalence of mental distress among hospitalized medical-surgical inpatients in public hospitals, Addis Ababa, Ethiopia, $2020(\mathrm{n}=408)$ was 213 (53.1\%).

\section{Factor Associated with Mental Distress}

Those variables with a $p$-value of $\leq 0.25$ in the binary logistic analysis were entered into multiple logistic analysis using enter method to identify the independent factors associated with mental distress among hospitalized inpatients. In bivariate analysis, the covariates: marital status, educational status, occupation, monthly income, alcohol use, previous history of a psychiatric condition, contact with psychiatric counseling, family history of psychiatric illness, having a comorbidity, and time of hospital stay were associated with mental distress among hospitalized inpatients. In multiple logistic regression analysis, covariates: marital status, residence, occupation, alcohol, previous history of psychiatric illness, and comorbidity were associated with a $95 \%$ confidence interval.

Those who were married were almost 2.7 times more likely to develop mental distress relative to being unmarried [AOR=2.67; 95\% CI $(1.065,6.683)]$. Participants living in 
rural areas were nearly two times more associated with mental distress compared with those living in urban areas $[\mathrm{AOR}=1.85 ; 95 \%$ CI $(1.047,3.264)]$. Those respondents who were private sector employees had higher than two-fold risk of developing mental distress $[\mathrm{AOR}=2.21 ; 95 \% \mathrm{CI}$ $(1.001,4.900)]$ and those who were daily laborers had greater than 4 times risk of developing mental distress relative to those who were government employees $[\mathrm{AOR}=4.70 ; 95 \% \mathrm{CI}$ (1.218, 18.215)].

Regarding substance use, study participants who drank alcohol were almost 1.7 times more likely to develop mental distress than those who did not drink $[\mathrm{AOR}=1.68$; 95\% CI $(1.025,2.740)]$.

Study participants who had a history of previous psychiatric illness were 3.4 times more likely to develop mental distress than those with no history $[\mathrm{AOR}=3.40$; 95\% CI $(1.078,10.737)]$, and those inpatients who had a comorbidity were more than twice as likely to develop a mental disorder than those with no comorbidity [AOR= 1.93; 95\% CI (1.200, 3.094)] (Table 5).

\section{Discussion}

\section{Prevalence of Mental Distress}

The prevalence of mental distress in the current study was $53.1 \%$ (52.6\% in the medical ward, and 53.7\% in the surgical ward). This finding was relatively comparable with the study reported from Korea among surgical inpatients, South African hospitals, and elsewhere in Ethiopia in hospitalized inpatient caregivers were 48.0\%, 49.7\%, $54.6 \%$, and $56.7 \%$ respectively. ${ }^{12-15}$ The prevalence in this study was relatively lower than that from the studies conducted in Pakistan, Harari Regional State, Debre Markos, Felege Hiwot hospital, and Gondar University hospital, Ethiopia was $87.9 \%, 59.7 \%, 61 \%$, and $58.6 \%$ respectively. ${ }^{16-19}$ This variation might be as a result from global prioritizing of mental health problems, change in improving policy, service development and management protocol on mental health-related problems, ${ }^{20,21}$ and lifestyle modification of patients, change in patient safety within and after discharge from hospitals, relative increase in mental and psychological counseling and even change in methodological approach.

The prevalence in this study was relatively higher than the studies reported from Saudi Arabia, Iran, India, United Kingdom, Northeast Brazil, South Brazil, Uganda, and Nigeria which was $25.5 \%, 34.8 \%, 44.1 \%, 8.1 \%$, $27.1 \%, 33.7 \%, 22.5 \%$, and $22 \%$ respectively $^{22-29}$ and similarly higher than the studies reported from Vietnam, Jazan Province of Saudi Arabia, Southern Taiwan, Hawassa, Ethiopia, Amanuel mental health hospital, Ethiopia, Menelik II hospital, Ethiopia which was 5.4\%, $20.6 \%, 38 \%, 22.1 \%, 27.1 \%$, and $23.2 \%$ respectively. ${ }^{5,30-34}$ This variation might have resulted from a methodological difference or study population, where data were taken from chronic medical-surgical and trauma inpatients including intensive care unit inpatients, difference in screening and diagnostic questionnaire tool used; some researchers used Kessler scale, Burden Assessment Scale, Hospital Depression, Anxiety and Stress Scale to measure mental distress and other sociodemographic and environmental factors may have increased the prevalence of mental distress in this study.

\section{Factors Associated with Mental Distress in Hospitalized Inpatients}

In this study, marital status of being married was an important factor which was statistically associated with mental distress with almost 2.7 times more positively associated with distress than being unmarried. This result of the study was similarly consistent with the study reported from Korea, Gondar University hospital, Ethiopia, and Geneva University Hospital, Switzerland respectively. ${ }^{10,31,35,36}$ The reason that those who were married were more likely to develop mental distress might be because they held more responsibility in their home, eg, family and child care, imbalance of demand and supply of resources for their family during being paired and poor communication and socialization within the family and other socioeconomic factors might have caused the possible difference..

Inpatients living in rural areas were two times more significantly associated with having mental distress than those living in urban areas but, in other studies living in rural areas was not significantly associated with mental distress. This might have resulted from patients living in the rural districts possibly having a poor perception of lifestyle modification, relaxation, recreation, and other luxuries for the management of distress and low levels of seeking psychological and mental health counselors or consultations.

In this study being a private employee was more than 2 times positively associated with mental distress compared to being a government employee and this association was also similar and in line with the studies revealed from 
Table 5 Factors Associated with Mental Distress Among Study Participants in Public Hospitals, Addis Ababa, Ethiopia, 2020 ( $\mathrm{n}=408$ )

\begin{tabular}{|c|c|c|c|c|c|}
\hline \multirow[t]{2}{*}{ Variables } & \multirow[t]{2}{*}{ Category } & \multicolumn{2}{|c|}{ Mental Distress } & \multirow{2}{*}{$\begin{array}{l}\text { Crude Odds Ratio } \\
(95 \% \mathrm{Cl})\end{array}$} & \multirow{2}{*}{$\begin{array}{l}\text { Adjusted Odds Ratio } \\
(95 \% \mathrm{Cl})\end{array}$} \\
\hline & & Yes & No & & \\
\hline Marital status & $\begin{array}{l}\text { Single } \\
\text { Married } \\
\text { Divorced } \\
\text { Widowed }\end{array}$ & $\begin{array}{l}53 \\
136 \\
14 \\
10\end{array}$ & $\begin{array}{l}63 \\
101 \\
8 \\
16\end{array}$ & $\begin{array}{l}1.35(0.564,3.214) \\
2.15(0.939,4.94) \\
2.80(0.865,9.06) \\
1.00\end{array}$ & $\begin{array}{l}1.74(0.638,4.756) \\
2.67(1.065,6.683)^{*} \\
2.70(0.755,9.689) \\
1.00\end{array}$ \\
\hline Residence & $\begin{array}{l}\text { Rural } \\
\text { Urban }\end{array}$ & $\begin{array}{l}89 \\
124\end{array}$ & $\begin{array}{l}52 \\
136\end{array}$ & $\begin{array}{l}\mathrm{I} .88(1.234,2.85) \\
\mathrm{I} .00\end{array}$ & $\begin{array}{l}1.85(1.047,3.264)^{*} \\
1.00\end{array}$ \\
\hline Education & $\begin{array}{l}\text { Cannot read and write } \\
\text { Can read and write } \\
\text { Primary } \\
\text { Secondary } \\
\text { Higher education }\end{array}$ & $\begin{array}{l}54 \\
32 \\
54 \\
45 \\
28\end{array}$ & $\begin{array}{l}30 \\
29 \\
47 \\
42 \\
40\end{array}$ & $\begin{array}{l}2.57(1.332,4.963) \\
1.58(0.785,3.165) \\
1.64(0.882,3.05) \\
1.53(0.807,2.904) \\
1.00\end{array}$ & $\begin{array}{l}1.14(0.438,2.953) \\
0.77(0.304,1.965) \\
0.89(0.385,2.057) \\
0.86(0.382,1.946) \\
1.00\end{array}$ \\
\hline Occupation & $\begin{array}{l}\text { Government employee } \\
\text { Private worker } \\
\text { Merchant } \\
\text { Farmer } \\
\text { Housewive } \\
\text { Daily laborer } \\
\text { Others }\end{array}$ & $\begin{array}{l}25 \\
48 \\
27 \\
61 \\
29 \\
11 \\
12\end{array}$ & $\begin{array}{l}43 \\
36 \\
34 \\
37 \\
20 \\
5 \\
13\end{array}$ & $\begin{array}{l}1.00 \\
2.29(1.191,4.41) \\
1.37(0.674,2.76) \\
2.84(1.495,5.37) \\
2.50(1.174,5.297) \\
3.78(1.17,12.15) \\
1.59(0.629,4.010)\end{array}$ & $\begin{array}{l}1.00 \\
2.21(1.001,4.900)^{*} \\
1.57(0.651,3.790)^{*} \\
1.62(0.636,4.108) \\
1.93(0.729,5.089) \\
4.70(1.218,18.215)^{*} \\
1.82(0.590,5.616)\end{array}$ \\
\hline Monthly income & $\begin{array}{l}\text { Low } \\
\text { High }\end{array}$ & $\begin{array}{l}125 \\
88\end{array}$ & $\begin{array}{l}88 \\
100\end{array}$ & $\begin{array}{l}\mathrm{I} .6 \mathrm{I}(\mathrm{I} .087,2.397) \\
\mathrm{I} .00\end{array}$ & $\begin{array}{l}1.17(0.68 \mathrm{I}, \mathrm{I} .994) \\
1.00\end{array}$ \\
\hline Alcohol & $\begin{array}{l}\text { Yes } \\
\text { No }\end{array}$ & $\begin{array}{l}78 \\
135\end{array}$ & $\begin{array}{l}55 \\
133\end{array}$ & $\begin{array}{l}1.29(0.844,1.964) \\
1.00\end{array}$ & $\begin{array}{l}1.68(1.025,2.740)^{*} \\
1.00\end{array}$ \\
\hline Previous history of psychiatric illness & $\begin{array}{l}\text { Yes } \\
\text { No }\end{array}$ & $\begin{array}{l}14 \\
199\end{array}$ & $\begin{array}{l}4 \\
184\end{array}$ & $\begin{array}{l}3.24(1.05,10.01) \\
1.00\end{array}$ & $\begin{array}{l}3.40(1.078,10.737)^{*} \\
1.00\end{array}$ \\
\hline Psychiatric counseling & $\begin{array}{l}\text { Yes } \\
\text { No }\end{array}$ & $\begin{array}{l}12 \\
201\end{array}$ & $\begin{array}{l}5 \\
183\end{array}$ & $\begin{array}{l}2.19(0.75,6.32) \\
1.00\end{array}$ & $\begin{array}{l}1.53(0.413,5.685) \\
1.00\end{array}$ \\
\hline Family history of psychiatric illness & $\begin{array}{l}\text { Yes } \\
\text { No }\end{array}$ & $\begin{array}{l}40 \\
173\end{array}$ & $\begin{array}{l}21 \\
167\end{array}$ & $\begin{array}{l}\mathrm{I} .84(\mathrm{I} .040,3.24) \\
\mathrm{I} .00\end{array}$ & $\begin{array}{l}1.82(0.972,3.413) \\
1.00\end{array}$ \\
\hline Comorbidity & $\begin{array}{l}\text { Yes } \\
\text { No }\end{array}$ & $\begin{array}{l}100 \\
113\end{array}$ & $\begin{array}{l}57 \\
131\end{array}$ & $\begin{array}{l}2.03(1.348,3.068) \\
1.00\end{array}$ & $\begin{array}{l}1.93(1.200,3.094)^{*} \\
1.00\end{array}$ \\
\hline Hospital stay & $\begin{array}{l}<\text { I week } \\
\text { I-2 week } \\
>2 \text { week }\end{array}$ & $\begin{array}{l}69 \\
66 \\
78\end{array}$ & $\begin{array}{l}75 \\
53 \\
60\end{array}$ & $\begin{array}{l}1.00 \\
\mathrm{I} .35(0.83 \mathrm{I}, 2.204) \\
\mathrm{I} .4 \mathrm{I}(0.88,2.259)\end{array}$ & $\begin{array}{l}1.00 \\
\mathrm{I} .18(0.691,2025) \\
\mathrm{I} .13(0.672, \mathrm{I} .896)\end{array}$ \\
\hline
\end{tabular}

Note: *Statistically significant at $\mathrm{p}$-value $<0.05$.

Abbreviation: $\mathrm{Cl}$, confidence interval.

Vietnam and Switzerland. ${ }^{5,35,36}$ This might be as a result from poor lifestyle enjoyment and devoting their time to the work place and workload, payment paid to them, poor administration and management system and having relatively low awareness. Being a daily laborer was the highest statistically associated variable, which was almost five times more highly associated with mental distress compared to being a government employee, which might be as a result of having low income to fulfill their daily allowance, living alone and far from their family, sometimes lacking work and workload at a point of time.

Inpatients who drank alcohol were almost 1.7 times more likely to be associated with mental distress than those who did not drink alcohol. This result was extended to the study done in Australia, Gondar University hospital, Ethiopia, and Geneva University Hospital, Switzerland. ${ }^{10,37,38}$ The reason 
might have resulted from the fact that people with alcohol abuse are responsible for neuropsychiatric disorders, domestic violence, child abuse, and neglect and productivity loss and also meet the diagnostic criteria for the majority of mental disorders, and sometimes they may develop distress in their life after time. ${ }^{39}$

Participants who had a previous history of psychiatric illness had highly increased vulnerability to mental distress. Those with previous history of psychiatric illness were 3.4 times more highly associated with mental distress than those who had no previous history of illness. This might be because patients who had a history of psychiatric illness may not have fully recovered from their illness; some negative and positive psychiatric symptoms may have been present and may have been included in the screening tool diagnostic criteria and positively associated with mental distress.

Respondents with comorbidities were twice as likely to be associated with mental distress as those who had no comorbidity. This result was similar to the studies reported from Jeddah of Saudi Arabia, Jazan Province of Saudi Arabia, India, South Africa, Menelik II hospital, Hawassa, and Harari Regional State hospitals of Ethiopia respectively. ${ }^{13,17,22,24,30,32,34}$ This outcome might have resulted because inpatients with two or more chronic comorbidities might have a different physical illness and the self-reporting questionnaire diagnostic tool also included some symptoms of physical illness and patients with comorbidity were limited in their daily physical activities; which might result in a high report of mental distress. ${ }^{11}$

\section{Strengths and Limitations}

This study has a couple of strengths. One, it used standardized and valid questionnaires. Secondly, many different variables were assessed and new variables were also added to assess mental distress among medical-surgical hospitalized adult inpatients. Our study also has some limitations. Firstly, medical-surgical hospitalized adult inpatients in private hospitals were not included. Secondly, the study was a cross-sectional study and did not describe a cause-effect relationship. Prospective and experimental studies are warranted.

\section{Conclusion}

The prevalence of mental distress among medical-surgical hospitalized inpatients in Addis Ababa public hospitals was high. Being married, rural residence, occupational status of being a private employee and daily laborer, drinking alcohol, previous history of psychiatric illness, and comorbidities were statistically associated with mental distress among hospitalized medical-surgical adult inpatients. Those healthcare providers who are working in hospitals should give special consideration to inpatients who are married, employees working in a private sector, daily laborers, those who drink alcohol, patients who have a previous history of psychiatric illness and comorbidities through their assessment and screening protocols by scheduling ongoing psycho-educational intervention that helps patients to cope with distress, empowering inpatients with knowledge and developing their competence in handling their illness and enhance their chance of living a life that is as healthy as possible.

\section{Abbreviations}

AAU, Addis Ababa University; AIDS, Acquired Immune Deficiency Syndrome; AOR, adjusted odds ratio; BSc, Bachelor of Science; CI, confidence interval; COR, crude odds ratio; DSM-IV, Diagnostic and Statistical Manual four; ETB, Ethiopian Birr; HFSUH, Hiwot Fana Specialized University Hospital; HIV, Human Immune Virus; MSc, Master of science; PI, Principal Investigator; SPSS, Statistical Package for Social Sciences; SRQ, Self-Reporting Questionnaire; SSQ, Social Support Questionnaire; TASH, Tikur Anbessa Specialized Hospital; USA, United States of America; WHO, World Health Organization.

\section{Data Sharing Statement}

Upon a reasonable request, data are available from the corresponding authors only.

\section{Ethics Approval and Consent to Participate}

Ethical clearance was obtained from Addis Ababa University, School of Nursing, and Midwifery Institutional Review Board and permission was sought from each data collection site. Written informed consent was obtained from each selected participant to confirm their willingness, and the study was conducted following the Declaration of Helsinki. Explanation of the survey purpose, description of the benefits, and an offer to answer all inquiries was made to the respondents. Also, the affirmation that they were free to withdraw consent and to discontinue participation without any form of prejudice was made. Privacy and confidentiality of collected information were ensured throughout the process as no names were written down. Patients who had severe mental distress due to mental illness were linked to the psychiatry unit within their hospital for intervention. 


\section{Acknowledgments}

We would like to give thanks to each hospital manager and the study participants for allowing and providing us relevant information. We also want to forward our gratitude to data collectors and supervisors. The authors' acknowledged this paper was available on the Addis Ababa University website as a thesis in June $2020 .{ }^{40}$

\section{Author Contributions}

All authors contributed to data analysis, drafting or revising the article, gave final approval of the version to be published, agreed to the submitted journal, and agree to be accountable for all aspects of the work.

\section{Disclosure}

The authors report no conflicts of interest in this work.

\section{References}

1. Samele C, Frew S, Urquia N. Mental health systems in the European union member states, status of mental health in populations and benefits to be expected from investments into mental health: European profile of prevention and promotion of mental health (EuroPoPP-MH):[main Report]. European Commission, Executive Agency for Health and Consumers Tender; 2013.

2. Sadock BJ. Kaplan \& Sadock's Synopsis of Psychiatry: Behavioral Sciences/Clinical Psychiatry; 2007. Philadelphia: Wolter Kluwer/ Lippincott Williams \& Wilkins, cop.

3. National Health Systems Resource Centre. National Health Accounts Estimates for India 2014-15. Gov India; 2017. Available from: https://www.google.com/search?client=firefox-b-d\&q=National + Health + Systems + Resource + Centre. + National + Health + Accounts + Estimates + for + India $+2014-15 .+$ Gov + India $+\% 5$ BInternet $\% 5 \mathrm{D}$. $+2017 \% 3$ B. Accessed July 27, 2021.

4. Connie LC. Post-traumatic stress disorder. Hong Kong Pract. 2017;39(1):14-18.

5. Bao Giang K, Viet Dzung T, Kullgren G, Allebeck P. Prevalence of mental distress and use of health services in a rural district in Vietnam. Glob Health Action. 2010;3(1):2025. doi:10.3402/gha.v3i0.2025

6. Risal A. Common mental disorders. Kathmandu Univ Med J. 2011;9 (3):213-217. doi:10.3126/kumj.v9i3.6308

7. Sim K, Rajasoorya C, Lam K, Chew L, Chan Y. High prevalence of psychiatric morbidity in a medical intensive care unit. Singapore Med J. 2001;42(11):522-525.

8. Marcolino J, Mathias L, Piccinini Filho L, Guaratini ÁA, Suzuki FM, Alli L. Hospital Anxiety and Depression Scale: a study on the validation of the criteria and reliability on preoperative patients. Rev Bras Anestesiol. 2007;57(1):52-62.

9. Federal Democratic Republic of Ethiopia Central Statistical Agency Population Projection of Ethiopia for all regions at Wereda level from 2014 - 2017; 2013. Available from: https://www.statsethiopia.gov.et/wpcontent/uploads/2019/05/Population-Projection-At-Wereda-Level-from2014-2017.pdf. Accessed July 27, 2021.

10. Alemu WG, Malefiya YD, Bifftu BB. Mental distress among patients admitted in Gondar university hospital: a cross-sectional institution-based study. Health Sci J. 2016;10(6):1.
11. Youngmann R, Zilber N, Workneh F, Giel R. Adapting the SRQ for Ethiopian populations: a culturally-sensitive psychiatric screening instrument. Transcult Psychiatry. 2008;45(4):566-589. doi:10.1177/ 1363461508100783

12. Jho HJ, Choi JY, Kwak KS, et al. Prevalence and associated factors of anxiety and depressive symptoms among bereaved family members of cancer patients in Korea: a nationwide cross-sectional study. Medicine. 2016;95(22):e3716. doi:10.1097/MD.0000000000003716

13. Peltzer K, Pengpid S, Skaal L. Prevalence of psychological distress and associated factors in urban hospital outpatients in South Africa. $S$ Afr J Psychiatry. 2012;18(1):10-15. doi:10.4102/sajpsychiatry.v18i1.304

14. Sintayehu M, Mulat H, Yohannis Z, Adera T, Fekade M. Prevalence of mental distress and associated factors among caregivers of patients with severe mental illness in the outpatient unit of Amanuel Hospital, Addis Ababa, Ethiopia, 2013: cross-sectional study. J Mol Psychiatry. 2015;3(1):1-10. doi:10.1186/s40303-015-0014-4

15. Aklil H, Alemnesh M, Kalayou KB, Haftu BG, Alemseged A. Assessment of depression prevalence and its determinants among adult patients admitted in governmental hospitals, Mekelle, Tigray, Ethiopia, 2012. a cross-sectional study. Int J Pharm Sci Res. 2013;4(5):1882-1892.

16. Rahman AS, Aziz A, Jamal Q, Siddiqui MA, Riaz M, Ali R. Prevalence of recognized and unrecognized depression among medical and surgical patients in a tertiary care hospital. J Pak Med Assoc. 2015;65(12):1320-1324.

17. Tilahun H, Awoke N, Geda B, Mesfin F. Depression and associated factors among adult inpatients at public hospitals of Harari regional state, eastern Ethiopia. Psychiatry J. 2018;2018:1-6. doi:10.1155/ 2018/6743520

18. Mulugeta H, Ayana M, Sintayehu M, Dessie G, Zewdu T. Preoperative anxiety and associated factors among adult surgical patients in Debre Markos and Felege Hiwot referral hospitals, Northwest Ethiopia. BMC Anesthesiol. 2018;18(1):1-9. doi:10.1186/ s12871-018-0619-0

19. Wondale GA, Yewunetu DM. Prevalence and associated factors of common mental disorders among patients admitted in Gondar university hospital medical and surgical wards, northwest Ethiopia, 2013. Am J Psychiatry Neurosci. 2015;2(3):43-49.

20. World Health Organization (WHO). Seventh meeting of the European national counterparts for the WHO European Mental Health Programme: report on a WHO meeting, Copenhagen, Denmark 11-13 December 2003. Copenhagen: WHO Regional Office for Europe; 2003.

21. Mnookin S. Out of the shadows: making mental health a global development priority. Washington, D.C.: World Bank Group; 2016.

22. Alzahrani A, Alghamdi A, Alqarni T, Alshareef R, Alzahrani A. Prevalence and predictors of depression, anxiety, and stress symptoms among patients with type II diabetes attending primary healthcare centers in the western region of Saudi Arabia: a cross-sectional study. Int J Ment Health Syst. 2019;13(1):1-7. doi:10.1186/s13033019-0307-6

23. Mirzaei M, Ardekani SMY, Mirzaei M, Dehghani A. Prevalence of depression, anxiety and stress among the adult population: results of Yazd health study. Iran J Psychiatry. 2019;14(2):137.

24. Ahlawat R, Tiwari P, D'Cruz S. Prevalence of depression and its associated factors among patients of chronic kidney disease in a public tertiary care hospital in India: a cross-sectional study. Saudi J Kidney Dis Transpl. 2018;29(5):1165. doi:10.4103/1319-2442.243972

25. Yohannes AM, Alexopoulos GS. Depression and anxiety in patients with COPD. Eur Respir Rev. 2014;23(133):345-349. doi:10.1183/ 09059180.00007813

26. Santos-Veloso MAO, Melo M, Cavalcanti RAN, Bezerra LS, ChavesMarkman ÂV, Lima S. Prevalence of depression and anxiety and their association with cardiovascular risk factors in Northeast Brasil primary care patients. Rev Assoc Med Bras. 2019;65:801-809. doi:10.1590/1806-9282.65.6.801 
27. Gullich I, Ramos AB, Zan TRA, Scherer C, Mendoza-Sassi RA. Prevalence of anxiety in patients admitted to a university hospital in southern Brazil and associated factors. Rev Bras Epidemiol. 2013;16:644-657. doi:10.1590/S1415-790X2013000300009

28. Wagner GJ, Ghosh-Dastidar B, Akena D, et al. Depression and its relationship to work status and income among HIV clients in Uganda. World J AIDS. 2012;2(3):126. doi:10.4236/wja.2012.23018

29. Salihu AS, Udofia O. Prevalence and associated factors of depression among general outpatients in a tertiary institution in Kano, North-Western Nigeria. Open J Psychiatry. 2016;6(3):228-236. doi:10.4236/ojpsych.2016.63028

30. Madkhali JM, Hakami AA, Dallak AH, et al. Prevalence and associated factors of depression among patients with diabetes at Jazan Province, Saudi Arabia: a cross-sectional study. Psychiatry J. 2019;2019:1-6. doi:10.1155/2019/6160927

31. Chiou Y-J, Chiu N-M, Wang L-J, et al. Prevalence and related factors of psychological distress among cancer inpatients using routine Distress Thermometer and Chinese Health Questionnaire screening. Neuropsychiatr Dis Treat. 2016;12:2765. doi:10.2147/ NDT.S118667

32. Duko B, Erdado M, Ebrahim J. Prevalence and factors associated with depression among hospital admitted patients in South Ethiopia: a cross-sectional study. BMC Res Notes. 2019;12(1):1-4. doi:10.1186/s13104-019-4109-3

33. Seid S, Demilew D, Yimer S, Mihretu A. Prevalence and associated factors of mental distress among caregivers of patients with epilepsy in Ethiopia: a cross-sectional study design. Psychiatry $J$ 2018;2018:1-8. doi:10.1155/2018/2819643
34. Bedasso K, Bedaso A, Feyera F, Gebeyehu A, Yohannis Z. Prevalence of common mental disorders and associated factors among people with glaucoma attending the outpatient clinic at Menelik II Referral Hospital, Addis Ababa, Ethiopia. PLoS One. 2016;11(9):e0161442. doi:10.1371/journal.pone.0161442

35. Costanza A, Amerio A, Odone A, et al. Suicide prevention from a public health perspective. What makes life meaningful? The opinion of some suicidal patients. Acta Biomed. 2020;91(Suppl 3):128.

36. Baertschi M, Costanza A, Canuto A, Weber K. The function of personality in suicidal ideation from the perspective of the interpersonal-psychological theory of suicide. Int $J$ Environ Res Public Health Rev. 2018;15(4):636. doi:10.3390/ijerph15040636

37. Yiengprugsawan V, Seubsman S-A, Sleigh AC. Psychological distress and mental health of Thai caregivers. Psychol Well Being Theory Res Pract. 2012;2(1):1-11. doi:10.1186/2211-1522-2-4

38. Costanza A, Rothen S, Achab S, et al. Impulsivity and impulsivity-related endophenotypes in suicidal patients with substance use disorders: an exploratory study. Int $J$ Ment Health Addict. 2020. doi:10.1007/s11469-020-00259-3

39. World Health Organization (WHO). Investing in mental health. World Health Organization; 2003. Available from: https://apps.who. int/iris/handle/10665/42823. Accessed July 27, 2021.

40. Shegaw T. Prevalence of Mental Distress and Associated Factors Among Hospitalized Medical-Surgical Adult Inpatients in Public Hospitals, Addis Ababa, Ethiopia, 2020 [dissertation]. Addis Ababa. Available from: Available from: http://etd.aau.edu.et/handle/ 123456789/ 595 24358. Accessed July 27, 2021.
Psychology Research and Behavior Management

\section{Publish your work in this journal}

Psychology Research and Behavior Management is an international, peer-reviewed, open access journal focusing on the science of psychology and its application in behavior management to develop improved outcomes in the clinical, educational, sports and business arenas. Specific topics covered in the journal include: Neuroscience, memory and decision making; Behavior modification and management; Clinical applications; Business and sports performance management; Social and developmental studies; Animal studies. The manuscript management system is completely online and includes a very quick and fair peer-review system, which is all easy to use. Visit http://www. dovepress.com/testimonials.php to read real quotes from published authors. 